\title{
Reflexões acerca da Política Nacional de Saúde Integral LGBT nas regiões de fronteiras
}

\author{
Reflections about the LGBT National Policy of Integral Health on the border \\ regions
}

\author{
Reflexiones sobre la Política Nacional de Salud Integral LGBT en las \\ regiones de frontera
}

\author{
Lislei Teresinha Preuss ${ }^{1}$ \\ Dilermando Aparecido Borges Martins ${ }^{1}$
}

Recebido em 06/04/2018; revisado e aprovado em 17/06/2018 aceito em 28/06/2018

DOI: http://dx.doi.org/10.20435/inter.v0i0.1922

\begin{abstract}
Resumo: Este artigo tem por objetivo correlacionar as regiões de fronteiras e população LGBT, em uma pesquisa exploratória de viés crítico-dialético, para estabelecer as pontes entre essas duas categorias de análise. Para tanto, a discussão parte das políticas de saúde, especialmente através da Política Nacional de Saúde Integral LGBT. São poucas as discussões sobre a temática, tampouco as ações voltadas para a saúde integral desta população nas regiões fronteiriças.
\end{abstract}

Palavras-chave: fronteiras; população LGBT; saúde.

Abstract: This article has as objective to correlate the border regions and LGBT population, in a exploratory research of critical-dialectic point of view, to establish bridges between these two categories of analysis. Therefore, the discussion starts from health policies, especially through the LGBT National Policy of Integral Health. There are few discussions on the subject, even actions for integral health to this population on border regions.

Keywords: borders; LGBT population; health.

Resumen: Este artículo tiene por meta correlacionar las regiones de frontera y la población LGBT en una búsqueda exploratoria con parcialidad crítico-dialéctico, para establecer las puentes entre estos dos categorías de análisis. Pata tanto, la discusión parte de las políticas de salud, especialmente a través de la Política Nacional de Salud Integral LGBT. Son pocas las discusiones sobre la temática, tampoco las acciones para la salud integral de esta población en las regiones de frontera.

Palabras clave: frontera; población LGBT; salud.

\section{INTRODUÇÃo}

Este artigo tem por objetivo problematizar de que modo as regiões fronteiriças têm sido inseridas na agenda pela Política Nacional de Saúde Integral para a população de Lésbicas, Gays, Bissexuais, Travestis e Transexuais (LGBT). A temática é emergente e contribui para ampliar o debate, saberes e práticas sobre as garantias do direito à saúde desse segmento nesse espaço geográfico.

Tratar do direito à saúde abarca uma série de discussões que permitem um direcionamento para várias searas e grupos específicos. O recorte que se dá neste artigo volta-se para um grupo em condição de vulnerabilidade, a população LGBT, posto que esta convive com violências diárias, preconceitos e outras situações que acabam por influenciar na sua saúde (BRASIL, 2013).

Por saúde, engloba-se não apenas a ausência de doenças, mas diversos outros fatores que contribuem para uma nova visão integradora, passando pelo bem-estar físico, mental e social, tornando-a um direito garantido constitucionalmente, preocupando-se com as determinantes

\footnotetext{
${ }^{1}$ Universidade Estadual de Ponta Grossa (UEPG), Ponta Grossa, Paraná, Brasil.
} 
sociais e construindo, assim, um sistema complexo que objetiva a valorização da vida humana (BATISTELLA, 2007).

Um dos princípios norteadores do Sistema Único de Saúde (SUS) é a "igualdade da assistência à saúde, sem preconceitos ou privilégios de qualquer espécie" (BRASIL, 1990). Isto permite que sejam realizadas políticas específicas para determinados grupos, a fim de que esses preconceitos sejam extintos e a igualdade de assistência exista de fato.

Um desses grupos, a população LGBT, pode ser considerada uma população vulnerável, conforme identificado pelo Instituto de Pesquisa Econômica Aplicada (IPEA) em 2012, pois esse grupo está exposto a uma violência maior, o que afeta diretamente em sua saúde de modo amplo, levando em conta diversos elementos como raça, idade, etnia, pobreza, escolaridade, dentre outras. Todos estes fatores levam a uma exposição deste grupo a agravantes que permitem a ocorrência de um abalo na saúde (PAULA; SILVA; BITTAR, 2017).

No âmbito da saúde, são inúmeros os fatores que influenciam nessa desigualdade e no preconceito dela decorrente. De acordo com as Nações Unidas no Brasil (2016), o preconceito contra homossexuais, um dos segmentos da população em análise, associado à desinformação relativa às questões de gênero, acaba por desembocar em um atendimento de má qualidade, resultando inclusive na recusa de atendimento por parte de alguns profissionais - que nem sempre estão preparados para atender essa população.

Além disto, importante gerador de preconceito pertinente ao grupo como um todo é o desrespeito ao uso do nome social, o que gera um mal estar desnecessário e uma violência em especial em travestis-, afetando diretamente na sua saúde e bem-estar (BRASIL, 2013). Esse estigma coloca, ainda, mulheres lésbicas e bissexuais em situações desconfortáveis para assumir sua sexualidade em consultas médicas, por falta de qualificação e preconceito dos profissionais da saúde (BARBOSA; FACCHINI, 2009).

Nesse sentido, a Política Nacional de Saúde Integral LGBT é criada com a finalidade de reduzir esses abalos, visando atender aos problemas dessa população específica e dar resposta às desigualdades decorrentes da falta de acesso à saúde, dos preconceitos, exclusão social e demais fatores fundamentais que levam esse grupo a ser considerado vulnerável.

A área da saúde tem sido considerada como importante indutor e parte constitutiva do modelo de desenvolvimento, reconhecido em diversos campos de pesquisas e ganhando expressão internacional na Organização Mundial da Saúde (OMS). A saúde configura-se como

[...] uma das principais áreas a serem planejadas, seja pela necessidade de abordagem e planejamento territorial regional da saúde, seja porque fronteiras epidemiológicas não se restringem a delimitações políticas e institucionais entre países. O planejamento das ações de saúde na fronteira necessariamente coloca a questão das relações com os territórios vizinhos. (GADELHA; COSTA, 2007, p. 215).

Considerando que o Brasil possui uma diversidade social, econômica, geográfica, étnica e cultural bastante significativa, as fronteiras ganham destaque, pois apresentam indicadores de concentração de renda e de desigualdades regionais preocupantes. Na realidade fronteiriça brasileira, acentuam-se as desigualdades étnicas, de classe social, nacionalidade, empobrecimento, evidenciando, também, uma situação de total desamparo no campo sanitário (FAGUNDES; KREUTZ; CASTAMAN, 2018), agravando e acentuando as iniquidades em saúde.

A nova dinâmica mundial impulsionada com o desenvolvimento de tecnologias de comunicações e transporte, resultou em uma constante mobilização de grandes volumes de pessoas e 
bens entre países e continentes em um período curto (GADELHA; COSTA 2007). Com a diminuição das barreiras espaciais e temporais, é possível viajar entre diversas partes do mundo em um tempo inferior ao período de incubação de muitas doenças. No intenso movimento de pessoas, animais e bens, estes são componentes importantes na distribuição de doenças no mundo. Em tal contexto, as fronteiras dos países tornaram-se mais abertas para a circulação e entrada de doenças, assim como seus vetores (OLIVEIRA, 2015; WILDER SMITH; HILL; FREEDMAN, 2008).

Há uma tendência de que os piores indicadores de saúde se concentrem nas fronteiras (OPAS/OMS, 2002). Essas regiões, consideradas marginalizadas, têm diferentes características socioepidemiológicas e possuem dificuldade de acesso aos bens e aos serviços públicos, historicamente abandonadas pelo Estado e pela falta de coesão social, por problemas de segurança pública e pelas precárias condições de cidadania.

Tradicionalmente tratada como local de peculiaridades culturais, caracterizada pelo baixo desenvolvimento socioeconômico e balizada por profundas iniquidades sociais, nas regiões de fronteira é que existe uma significativa procura pelos serviços públicos de saúde no Brasil, seja pela facilidade e/ou qualidade de atendimento, seja pela ineficiência do sistema dos países vizinhos, seja pela urgência e/ou emergência do tratamento (PREUSS, 2007).

É diante desse cenário que se busca problematizar a relação entre estas três importantes categorias: saúde, população LGBT e regiões de fronteiras. Para tanto, este artigo está assim estruturado: no primeiro item, discute-se o que é saúde e como a população LGBT nela se insere, especialmente através da Política de Saúde Integral LGBT; em seguida, é colocada em debate a questão da territorialidade e como a saúde da população LGBT é tratada nesses locais, buscando compreender a conexão existente entre tais temáticas para, enfim, trazer as considerações finais e as percepções apreendidas em tal discussão. O estudo se embasa no método dialético-crítico, envolvendo uma pesquisa exploratória, cujo levantamento dos dados se baseia em fontes documental e bibliográfica.

\section{SAÚDE E POPULAÇÃO LGBT}

Com a Constituição Federal de 1988, o Estado passa a adotar um modelo de saúde inserido no contexto da seguridade social, conforme predispõe o artigo 194 da Carta Constitucional. Desse modo, a saúde nada mais é do que um dos direitos sociais, ou seja, "[...] prestações positivas proporcionadas pelo Estado direta ou indiretamente, enunciadas em normas constitucionais, que possibilitam melhores condições de vida aos mais fracos, direitos que tendem a realizar a igualização de situações sociais desiguais" (SILVA, 2005, p. 286).

A partir da Reforma Sanitária Brasileira, o conceito de saúde foi reformulado, passando a ser considerado como um direito de todos, e não ligado apenas ao aspecto curativo ou hospitalocêntrico. Ou seja, significa que são vários os aspectos que a circundam, como alimentação, habitação, educação, renda, trabalho, transporte, dentre vários outros fatores. De acordo com o relatório da 8 a Conferência Nacional de Saúde:

Direito à saúde significa a garantia, pelo Estado, de condições dignas de vida e de acesso universal e igualitário às ações e serviços de promoção, proteção e recuperação de saúde, em todos os seus níveis, a todos os habitantes do território nacional, levando ao desenvolvimento pleno do ser humano em sua individualidade. (BRASIL, 1986, p. 4).

Baseado nisto é que se firma o conceito de saúde, como um meio de se alcançar esses objetivos trazidos na Reforma, ou seja, um sistema capaz de atender a todos indistintamente 
e colocar em prática os direitos sociais, através da proteção social. De acordo com Fleury e Ouverney (2008), entende-se por proteção social modelos que visam a uma igualdade, variando de acordo com as sociedades e suas demandas específicas. Uma de suas tipologias é o modelo de seguridade social, em que o foco principal é a solidariedade e a redistribuição, tomando por base o princípio da justiça social, a fim de atender a universalização da cidadania.

Nesse sentido, o artigo 198 da Constituição Federal cria o Sistema Único de Saúde (SUS), com características próprias e que possam estabelecer os requisitos firmados na Reforma. Para Paim (2009, p. 46):

O acesso universal e igualitário às ações e serviços para a promoção, proteção e recuperação, tal como previsto pela Carta Magna, permite, portanto, desenvolver uma atenção integral à saúde. Em vez se limitar a uma assistência médica curativa, o direito à saúde no Brasil estende-se à prevenção de doenças, ao controle de riscos e à promoção da saúde. Assim, as ações e serviços de saúde são de relevância pública.

De acordo com o disposto, trata-se de uma rede regionalizada e hierarquizada, cujas diretrizes são a universalidade, a descentralização, a integralidade e a participação da comunidade, aqui abordadas sob a perspectiva de Maria Elisabeth Kleba (2005).

Primeiramente, a universalidade atribui como responsabilidade do Estado a viabilização da saúde como garantia de todos os cidadãos, assegurando o acesso aos serviços de saúde como um todo, além de assegurar condições de vida favoráveis à saúde, através da alimentação, moradia, saneamento, habitação, dentre outros. Isto foi possível, de maneira mais contundente, após a separação dos Ministérios da Previdência, Assistência e Saúde, estabelecendo as competências de cada um para garantir esta diretriz.

A integralidade, por sua vez, decorre da compreensão da saúde como um processo dependente de fatores biológicos, históricos, psicológicos e sociais. Isto significa que se deve levar em conta todas as condicionantes que tornam a vida do indivíduo mais saudável ou, ao contrário, a torna mórbida. Tal conceito da integralidade da saúde pode ser extraído do artigo $3^{\circ}$ da Lei $n$. 8080/1990, que assim dispõe:

Art. $3^{\circ}$ Os níveis de saúde expressam a organização social e econômica do País, tendo a saúde como determinantes e condicionantes, entre outros, a alimentação, a moradia, o saneamento básico, o meio ambiente, o trabalho, a renda, a educação, a atividade física, o transporte, o lazer e o acesso aos bens e serviços essenciais. (BRASIL, 1990).

É necessário, então, articular a saúde com demais setores da sociedade, pensando em uma política ampla, parcerias públicas e privadas em um caminho de ações para prevenção, promoção e recuperação.

Por descentralização entende-se a estratégia em prol da definição de competências para decisões concernentes à saúde, para garantir assim a universalidade e integralidade. É possível então atender as necessidades da população em nível local, em que a garantia à saúde se torna responsabilidade municipal, com autonomia institucional - inclusive financeira.

Por fim, a participação e o controle social vêm por reconhecer o indivíduo como cidadão, conferindo a ele direito de participar politicamente nas decisões relativas à saúde, podendo defender seus interesses. Esse mecanismo pode ser efetivado através da participação nas Conferências e Conselhos de Saúde, ambas existentes em todos os níveis da federação.

Sob esses pilares é que se firma o SUS, cujo conceito encontra-se no artigo $4^{\circ}$ da Lei $n$. 8080/1990, caracterizado por ações e serviços de saúde, dividido entre União, Estados e mu- 
nicípios, seja pela administração direta ou indireta. Detalhando mais o conceito, explicita Paim (2009, p. 54):

Portanto, o SUS corresponde a um sistema público de saúde formado por órgãos e instituições federais, estaduais e municipais. Não é exclusivamente constituído por organismos da administração direta, como o Ministério da Saúde e as secretarias municipais e estaduais correspondentes. Integram também o SUS os órgãos e instituições da chamada administração indireta, a exemplo das autarquias, fundações e empresas públicas. Assim, serviços e estabelecimentos de saúde vinculados à administração indireta poderiam gozar de maior autonomia de gestão, adequando-se à melhor natureza e às especificidades das ações de saúde. A iniciativa privada pode participar do SUS, em caráter complementar, mediante contrato regido pelo direito público. Neste sentido, os serviços privados e filantrópicos contratados funcionam como se público fossem.

Logo, o SUS é um sistema descentralizado, que visa atender a toda a população do país, baseado em princípios e características próprias, que estão voltadas para satisfazer os anseios do Movimento Sanitário e da própria Constituição Federal, posto que está em harmonia com os objetivos e fundamentos por ela trazidos.

A partir desse conceito, é que é possível estabelecer políticas voltadas a determinados segmentos da população, para que haja um tratamento igualitário na questão da saúde, como é o caso da população LGBT. Conforme Cardoso e Ferro (2012), essa população específica, por não se adequar a um padrão heteronormativo, acaba por ter direitos básicos agredidos, levando em consideração que diversos fatores os colocam em condição de vulnerabilidade, como a violação do direito à saúde - um direito social e, sobretudo, fundamental.

Importa resgatar o processo histórico desse grupo, a fim de compreender como foram se firmando no cenário brasileiro e quais foram as suas demandas desde o início de sua militância, especialmente em termos de saúde pública.

A população de Lésbicas, Gays, Bissexuais, Travestis e Transexuais passou a adotar tal nomenclatura - LGBT - a partir da $1^{\text {a }}$ Conferência Nacional de Gays, Lésbicas, Bissexuais, Travestis e Transexuais/GLBT, realizada em Brasília em junho de 2008. Tal mudança ocorreu com o objetivo de dar mais visibilidade às mulheres lésbicas, além de aproximar o termo com os definidos pelo padrão internacional (BRASIL, 2008).

O surgimento dessa população se deu a partir de um processo histórico que abrange diversos fatos marcantes, aqui abordados de modo sucinto. Sua aparição inicial se deu de acordo com o contexto internacional, uma vez que, na década de 1960, no pós-segunda guerra mundial, surgem indícios do primeiro movimento, à época denominado GLBTT - Gays, Lésbicas, Bissexuais, Travestis e Transgêneros (REIS, 2007).

No Brasil, esses grupos começaram a tomar força na mesma época, especialmente após a criação do grupo "Somos", em São Paulo. O grupo inicialmente era voltado apenas para homens homossexuais e, em seguida, passou a abarcar mulheres lésbicas, através do Grupo de Ação Lésbica-Feminista/GALF, cujo objetivo era partilhar suas dificuldades, momentos, demandas, dentre outros (SIMÕES; FACCHINI, 2009).

Em termos de saúde, houve uma eclosão do movimento homossexual e sua visibilidade a partir do surgimento do vírus HIV/Aids, que era predominantemente associado a esse segmento específico. Estes eram denominados grupos de risco e foram considerados, de modo geral, responsáveis pela proliferação do vírus no país (MARQUES, 2003). 
A luta contra o vírus, somado ao movimento da Reforma Sanitária e ao processo de redemocratização brasileira, possibilitou que o movimento homossexual, em específico, passasse a ganhar mais força. Ademais, outros grupos também passaram a se intensificar: as travestis se expunham através de performances artísticas, em casas culturais alternativas, além de fortalecer sua militância. Elas combatiam o impacto da Aids e o aumento dos casos de violência contra esse grupo em específico, posto que, na comunidade LGBT, eram os que mais se expunham (FACCHINI, 2011).

Nessa toada, a partir dos anos 1990, o movimento LGBT como um todo passa a se reestruturar e a se fortalecer. A partir de 1996, os encontros denominados de Seminários Nacionais de Lésbicas/Senales começam a ocorrer com frequência. Ainda, na segunda metade dessa década, os grupos transexuais passam a se firmar na luta por cirurgias de transgenitalização, que fora aprovada a partir de 1997 pelo Conselho Federal de Medicina (FACCHINI, 2011).

Com isto, diversos grupos foram se formando na luta por direitos para a comunidade LGBT como um todo. A $1^{\text {a }}$ Conferência Nacional LGBT demonstrou como o grupo havia se mobilizado e lutava por melhorias em todos os seus aspectos de vida. Com essas cobranças, o movimento social adquire algumas conquistas ao longo dos anos 2000, como a união homoafetiva, uso do nome social, adoção, além da criação de políticas públicas como o Brasil Sem Homofobia.

$\mathrm{Na}$ área da saúde, a mudança se deu através dessas conquistas que se direcionaram para outras áreas, abrangendo a saúde de modo integral, e não mais focada apenas no tratamento do HIV/Aids. Com isto, uma nova política de saúde é criada a fim de atender às demandas da população LGBT.

A atual política criada pelo Ministério da Saúde é a Política Nacional de Saúde Integral de Lésbicas, Gays, Bissexuais, Travestis e Transexuais, promulgada pela Portaria no 2.836 , de $1^{\circ}$ de dezembro de 2011. De acordo com a Política, sua marca principal é o reconhecimento de que a discriminação e a exclusão acabam por atingir essa população, afetando seu processo de saúde-doença. Para tanto, o que se pretende é realizar mudanças na determinação social da saúde, diminuindo principalmente as desigualdades que a circundam (BRASIL, 2013).

O Plano vai explicitar os fundamentos que justificam a sua criação, sejam eles legais ou sociais. Primeiramente, lista que os problemas de travestis e transexuais não se resumem apenas à AIDS, como ocorria a priori, afirmando que os seus problemas de saúde são bem mais complexos do que isto, como uso de drogas, silicone industrial, hormônios e outros medicamentos. Disto decorre depressão e crise de ansiedade, por exemplo. Atribuem os problemas, ainda, ao mau atendimento dos serviços de saúde que têm experiência restrita em lidar com a feminilidade de transexuais. A falta de respeito ao uso do nome social e a violência sofrida pela população LGBT também podem ser elencadas como justificativas para criação de uma política específica para esse grupo (BRASIL, 2013).

O artigo $1^{\circ}$ da Política traz o objetivo geral a que ela se destina, ou seja, eliminar a discriminação e o preconceito institucional para reduzir desigualdades e transformar o SUS, de fato, em um sistema universal, integral e equitativo - retomando os conceitos base do Sistema de Saúde e a consolidação dos anseios trazidos na Reforma Sanitária. Já os objetivos específicos são distribuídos em vinte e três incisos, presentes no artigo $2^{\circ}$ da Portaria. Dentre eles, destacam-se: a ampliação de acesso da população LGBT aos serviços de atendimento do SUS (II); qualificar o rede de atendimento do SUS para dar melhor atenção a população LGBT (III); coleta de dados e análise acerca da saúde LGBT (IV); criar estratégias para diminuir a mortalidade de travestis (IX); 
cuidado e saúde de adolescentes e idosos LGBT (X); oferecer atenção integral às DST's no âmbito do SUS (XI); eliminar os preconceitos nos serviços de saúde (XVI); garantia do uso do nome social aos usuários do SUS (XVII) (BRASIL, 2013).

Os artigos $4^{\circ}, 5^{\circ}$ e $6^{\circ}$ trazem, respectivamente, as competências da Federação, dos Estados e dos Municípios, relembrando o princípio da descentralização da saúde e fixando os limites e cooperação de cada ente, a fim de efetivar a Política e atender os anseios da comunidade LGBT.

Com a criação dessa Política Pública, nota-se uma conquista da população LGBT a partir do momento em que a sociedade civil se articula em busca de efetivação de direitos e melhoria na qualidade de vida desse grupo. São debates que envolvem os poderes Executivo, Legislativo e Judiciário, além de toda a sociedade civil, os quais trabalham questões mais variadas como a eliminação de todas as formas de discriminação social, identidade de gênero, união entre pessoas do mesmo sexo - bem como a adoção de crianças por esses casais - autonomia do próprio corpo e a questão de nova identidade civil para travestis e transexuais (MELLO; BRITO; MAROJA, 2012). Acredita-se que essas questões podem influenciar, em última análise, nas condições de vida dessa população vulnerável, já que efetivar suas demandas implica seu bem-estar físico e mental, incidindo no conceito ampliado de saúde.

\section{TERRITORIALIDADE E POLÍTICA DE SAÚDE LGBT}

As fronteiras na atualidade têm-se caracterizado como lugar de contato, lugar de passagem, espaço de relações, de ideias, comunicação e troca e não um espaço de separação ou barreira. A mobilidade na região de fronteira brasileira tem características peculiares, destacando, por exemplo, sua dimensão e extensão territorial.

Nesse cenário, há um aumento dos fluxos e intercâmbios de pessoas, serviços e produtos decorrentes dos processos de integração regional, repercutindo diretamente nos indicadores sanitários e demográficos das cidades fronteiriças, que se tornam corredores econômicos. As assimetrias dos sistemas de atendimento à saúde dos diferentes países provocam um fluxo em direção ao país de melhor situação, sobrecarregando os sistemas de saúde locais. A gratuidade e universalidade do atendimento de saúde no Brasil é o maior fator de atração de pacientes de outros países (GIOVANELLA, 2004).

As fronteiras não são empecilho para a circulação de doenças, pois doenças desconhecem fronteiras. São consideradas áreas mais vulneráveis à sua transmissão, devido a intensidade e multiplicidade de interações que aí se efetuam, tornando o controle das doenças ainda mais difícil $^{2}$. As fronteiras apresentam grande mobilidade e população flutuante, estão expostas às migrações, pessoas em busca de oportunidades de trabalho, a prática do tráfico e prostituição.

Do ponto de vista da saúde pública, a fronteira tem que ser vista como uma franja territorial dinâmica, que constitui uma unidade epidemiológica com processo de troca espacial, demográfica, socioeconômica e cultural, que dilui as particularidades nacionais e determina

\footnotetext{
${ }^{2}$ No que diz respeito aos efeitos das fronteiras na difusão de doenças, de acordo com Peiter (2005), em zonas de fronteira é que as diversas redes sociais que se interconectam, colocando em contato pessoas das mais diversas regiões dos países lindeiros, com diferentes graus de susceptibilidade (diferentes histórias imunológicas), que muitas vezes correspondem a padrões epidemiológicos muito distintos dos nacionais. São comuns surtos de sarampo, febre amarela e outras doenças plenamente controladas no Brasil, devido a falhas da cobertura vacinal nos países lindeiros. A alta receptividade com a significativa presença de grupos populacionais altamente móveis, também contribui para a a renovação constante de populações susceptíveis na região, potencializando os processos de transmissão de doenças.
} 
problemas sanitários reais e potenciais, às vezes específicos, obrigando a realização de atividades nacionais conjuntas para seu controle. (BRASIL, 2007).

Reconhecem-se, nesse aspecto, os problemas próprios dos sistemas de saúde dos países latino-americanos, devido às assimetrias na distribuição de serviços sanitários, além da diversidade de concepções, componentes valorativos da população sobre as questões que dizem respeito à saúde. Isto agrava as desigualdades sociais e iniquidades nas regiões situadas ao longo da linha da fronteira (GIOVANELLA et al., 2005 apud PREUSS, 2011).

$\mathrm{Na}$ área da fronteira, o principal empecilho para materialização do direito à saúde é a exacerbação da desigualdade territorial que atua perversamente e marca o processo de exclusão sanitária. A fruição do direito à saúde implica efeitos concretos no âmbito das políticas públicas, necessidades locais de saúde, incorporando, assim, ao direito universal à saúde, a análise da determinação social do processo saúde-doença (FAGUNDES; KREUTZ; CASTAMAN, 2018).

Uma das discussões que surge acerca da saúde em geral consiste na questão da territorialidade, especialmente nas fronteiras. Ao tratar da Política Nacional de Saúde Integral LGBT, o embate não foge à questão, importando discutir se é possível que a população de fronteiras seja também público-alvo da Portaria do Ministério da Saúde.

Sobre a Política Nacional, de modo geral, não há nenhuma menção às áreas de fronteiras. A categoria território é destacada na referência de gênero, raça, cor e território, e das especificidades em saúde da população LGBT nos artigos 2o dos objetivos específicos da Política Nacional de Saúde Integral LGBT e 3으 na elaboração dos planos, programas, projetos e ações de saúde.

Entretanto é necessário levar em consideração a possibilidade de diálogo entre esses dois grupos específicos. Ao criar uma política pública que vai pensar na saúde, de modo amplo, para a população LGBT, é fundamental levar em consideração de que forma essa política deve ser aplicada na região fronteiriça. Isto porque estas são regiões que implicam em maior vulnerabilidade em questões de saúde como um todo.

As regiões de fronteiras apresentam configurações sociais e econômicas que demandam uma intervenção governamental, especialmente por questões ligadas ao contrabando e tráfico de drogas, aumentando-se assim as taxas de homicídio e violência (SALLA et al., 2014). Esses elementos refletem diretamente na questão da saúde populacional, uma vez que são aspectos que impactam a sociedade como um todo, elevando a demanda por atendimento em saúde, além de afetar o bem-estar da população na perspectiva da saúde integral defendida no presente artigo. Tudo isto demonstra uma necessidade efetiva de proteção e de políticas públicas nessas regiões específicas, o que leva a um impacto direto no desenvolvimento local.

A Política Nacional de Saúde Integral LGBT considera que um dos segmentos desse grupo, as travestis, exercem em suas relações sociais - nas ruas - a sua feminilidade, mas também utilizam esses espaços como porta de entrada para o uso de drogas e exposição à violência (BRASIL, 2013).

Ao considerar que, nas fronteiras, as taxas de homicídio e violência são ainda mais altas e o tráfico de drogas é intenso, é possível estabelecer uma relação entre esses espaços e as travestis, por exemplo, posto que sua exposição é ainda maior e a possibilidade de se encontrar em uma situação de vulnerabilidade se eleva mais.

Desse modo, as ações de promoção da saúde para a comunidade LGBT, em regiões fronteiriças, tornam-se ainda mais necessárias, posto que existe, nesses locais, uma espécie de dupla vulnerabilidade - por pertencer ao grupo e por viver em uma região onde a exposição é maior. 
Esse tipo de dificuldade se apresenta não apenas no Brasil, mas em outras regiões do mundo também. Um estudo realizado nos Estados Unidos da América, publicado no ano de 2018, tentou compreender como a população LGBT enfrentava as dificuldades no acesso à saúde em uma cidade fronteira entre o país e o México, território vizinho, denominada El Paso. Os dados apontam que transexuais, por exemplo, encontram dificuldades por sentir discriminação por parte dos atendentes, além da falta de recursos financeiros. Tal discriminação se dá, ainda, pelo fato de que grande parte da população local é hispânica (LOZA; ALVAREZ; PERALTA-TORRES, 2018).

Ao realizar uma analogia com regiões fronteiriças brasileiras, tal situação é passível de ocorrer em nosso país, uma vez que muitas imigrantes nessas regiões buscam tratamento no Estado brasileiro. A título exemplificativo, um estudo realizado em cidades fronteiras com os países da Argentina, Paraguai e Uruguai demonstrou que 75\% dos municípios entrevistados apontam a vinda de estrangeiros para utilizar o SUS, sendo que em 36\% desses casos são frequentes (GIOVANELLA et al., 2007).

Importante papel para a redução de desigualdades e enfrentamento aos preconceitos contra a população LGBT e que é fundamental em regiões fronteiriças é o MERCOSUL, um dos principais impulsionadores de políticas que integram os países que o compõem. Ao se tratar de saúde, tal comportamento não destoa, já que os objetivos do bloco são aprofundar a integração regional, reduzir as desigualdades e partilhar conhecimentos e boas práticas para desenvolver tal expectativa (MERCOSUL, s.d.).

São diversos os princípios que regem o bloco, dentre eles a solidariedade, respeito, equidade e benefício mútuo, ferramentas viáveis para que a integração entre os países ocorra, tornando-se uma potencia regional da América Latina.

Em relação à população LGBT, o MERCOSUL possui um comitê específico no âmbito da Reunião de Altas Autoridades sobre Direitos Humanos e Chancelarias (RAADH) do MERCOSUL e Estados Associados. Em suma, trata-se de um grupo que analisa e define políticas públicas de Direitos Humanos referente ao bloco, com a participação de seus membros e demais países associados, em reuniões semestrais. A RAADH foi criada no ano de 2004, através do Conselho do Mercado Comum, cujo principal objetivo é promover os direitos humanos (MERCOSUL, s.d.).

No ano de 2007, em Montevidéu, foi organizado o Seminário sobre Diversidade Sexual, Identidade e Gênero, com a finalidade de erradicar e discriminação e reconhecer os direitos de diversidade sexual como direitos fundamentais. Em 2008, foi criado um grupo de trabalho, que passou a se chamar Grupo de Trabalho LGBT a partir de 2010, cujo foco são os direitos humanos da população LGBT (MERCOSUL, s.d.).

Em sua reunião mais recente, datada de $1^{\circ}$ de junho de 2017, em Buenos Aires, com a presença de representantes da Argentina, Brasil, Paraguai, Uruguai e Bolívia, como Estados parte; além de Chile, Colômbia e Equador, como Estados associados, foram discutidos alguns pontos relativos à promoção de Direitos Humanos para a população LGBT. Destaca-se, aqui, a criação de um programa de capacitação para funcionários públicos referentes à matéria de direitos humanos para a comunidade LGBT, com foco para saúde, educação, trabalho, dentre outros que envolvam agentes públicos (MERCOSUL, s.d.)

Diante desse cenário, nota-se que o MERCOSUL possui preocupação com as políticas voltadas para a população LGBT, criando uma comissão específica para as demandas desse grupo. Ao se tratar da Política de saúde LGBT, no contexto brasileiro, é plausível estabelecer uma relação 
com o Bloco latino-americano, considerando que seu foco principal é criar um grupo de países capaz de crescer em conjunto.

A partir do momento em que os Estados membros do MERCOSUL firmam, entre eles, um acordo com a finalidade de promover o bem-estar da população LGBT, deve haver uma cooperação entre seus membros para que esse objetivo seja alcançado. Desse modo, embora o foco de discussão seja a Política Nacional de Saúde LGBT, deve-se levar em conta que a promoção do bem-estar desse grupo e de sua saúde integral é de responsabilidade dos demais países que fazem divisa com o Estado brasileiro.

Ainda que a área de saúde é a que tem apresentado, historicamente, um conjunto de iniciativas mais sistemáticas e abrangentes para a população LGBT, observam-se ações específicas de prevenção nas regiões de fronteiras brasileira relacionadas a doenças sexualmente transmissíveis (DST), HIV/AIDS, dentre outras.

Um desses exemplos é o projeto "AMAZONAIDS: Na Fronteira uma Epidemia", lançado no ano de 2008, como um dos objetivos à resposta da epidemia da Aids na região de fronteiras entre Brasil, Colômbia e Peru. Tal região engloba as cidades de Tabatinga, Atalaia do Norte e Benjamin Constant, situadas no estado do Amazonas.

Esse Projeto é de iniciativa do Programa Conjunto das Nações Unidas sobre HIV/Aids (UNAIDS), que em sua apresentação reforça a questão do estigma e preconceito como inimigos da saúde e parceiros diretos do vírus, uma vez que "Grupos vulneráveis, como prostitutas e a população LGBT, acabam duplamente estigmatizados quando o HIV e a aids somam-se ao preconceito que os cerca" (UNAIDS, 2016, p. 8).

Isto demonstra a vulnerabilidade existente na região, que foca apenas na questão do combate ao vírus do HIV/Aids, mas deixa de lado as demais ações de saúde voltadas para uma perspectiva da integralidade. Mais uma vez, ressalta-se a importância da atuação na região fronteiriça, nos termos da Política de Saúde Integral LGBT.

Percebe-se que as ações de saúde se voltam precipuamente para o combate ao vírus do HIV/Aids. Acredita-se que essa situação decorre devido ao caráter recente de institucionalização da Política Nacional de Saúde Integral para a população LGBT, enquanto que a luta por políticas de saúde voltadas para as DSTs/AIDS possue um caráter histórico mais amplo, que remontam à década de 1980 (BRASIL, 2013).

Portanto é de fundamental importância que os debates avancem nesse sentido, considerando as peculiaridades das regiões fronteiriças, bem como as dificuldades enfrentadas pela população em LGBT em termos de saúde pública, seja pela falta de acesso, seja pelo preconceito sofrido, o que afeta diretamente na saúde em sua integralidade. É preciso avançar um pouco mais para que se consolide, para a comunidade LGBT, um modelo de saúde universal, integral e equitativo.

\section{CONSIDERAÇÕES FINAIS}

Conforme sustentado, as regiões de fronteiras são locais que necessitam de uma atenção maior do Poder Público, especialmente através da criação de políticas públicas, considerando suas peculiaridades econômicas, geográficas e sociais. Tratando-se de saúde, essa necessidade se intensifica, devido ao fluxo de pessoas e o alto índice de violência, o que acarreta uma demanda ainda maior. 
A saúde deve ser considerada em seus variados aspectos, em uma perspectiva globalizada, levando em conta todas as condicionantes que a circundam, objetivando principalmente o bem-estar populacional. Nesse sentido é que surge a Política Nacional de Saúde Integral LGBT, com diversos aspectos que partem dessa concepção ampla para melhorar a saúde desse grupo vulnerável.

Em se tratando de fronteiras e desenvolvimento local, a Política não aprofundou tal temática, o que pode impactar diretamente nessas regiões específicas, se considerarmos suas necessidades. Desse modo, essa população que naturalmente sofre pelos preconceitos, marginalização e violência, tende a ser ainda mais discriminada, afetando diretamente a sua saúde.

As ações voltadas para a população LGBT, em regiões fronteiriças, são muito específicas, como é o caso da AMAZONAIDS, surgido em 2008, plano específico da ONU voltado para a região das fronteiras no Amazonas, com trabalhos direcionados para a luta contra o HIV/AIDS (UNAIDS, 2016). Porém, conforme foi apresentado e defendido no presente artigo, as questões de saúde voltadas para a população LGBT possuem uma dimensão maior, indo além do combate às DSTs, sendo o Plano de Saúde Integral mais aprofundado, demandando ações globais de prevenção e cuidados.

Portanto é imprescindível um adendo à Política, em que se contemplem, de modo mais detalhado, as ações voltadas para as regiões de fronteiras, seja através do Poder Público nacional, seja através da cooperação com o próprio MERCOSUL. Mais do que isto, é necessário de fato implementar tais ações trazidas na Política, a fim de reduzir as desigualdades para com a população LGBT, sua condição de vulnerabilidade, e aumentar o seu bem-estar para atingir o tipo ideal de saúde trazido pela Constituição Federal.

Há que se ressaltar, por fim, que este artigo apresenta apenas uma análise inicial acerca da temática, posto que se trata de uma pesquisa recente e com remotas fontes de acesso. Não há dúvidas quanto à necessidade de aprofundar mais as discussões sobre a saúde da população LGBT em fronteiras, haja vista as dificuldades apresentadas e a escassez de materiais nessa área.

\section{REFERÊNCIAS}

BARBOSA, Regina Maria; FACCHINI, Regina. Acesso a cuidados relativos à saúde sexual entre mulheres que fazem sexo com mulheres em São Paulo, Brasil. Cadernos de Saúde Pública, Rio de Janeiro, v. 25, supl. 2, s291-s300, 2009. Disponível em: http://www.scielo.br/pdf/csp/v25s2/11.pdf. Acesso em: 28 jan. 2018.

BATISTELLA, Carlos. Abordagens contemporâneas do conceito de saúde. In: FONSECA, A. F.; CORBO, A. D. (Org.). O território e o processo saúde-doença. Rio de Janeiro: EPSJV/Fiocruz, 2007. p. 51-86.

BRASIL. Ministério da Saúde. Política Nacional de Saúde Integral de Lésbicas, Gays, Bissexuais, Travestis e Transexuais. 1 ed., 1. reimp. Brasília: Ministério da Saúde, 2013.

BRASIL. Secretaria Especial de Direitos Humanos. Anais da Conferência Nacional de Gays, Lésbicas, Bissexuais, Travestis e Transexuais - GLBT. 2008. Disponível em: http://www.direito.mppr.mp.br/arquivos/ File/IConferenciaNacionaldeGaysLesbicasBissexuaisTravestiseTransexuaisGLBT.pdf. Acesso em: 12 jun. 2018.

BRASIL. Ministério da Saúde. Agência Nacional de Vigilância Sanitária. Resolução da Diretoria Colegiada - RDC N. 68, de 10 de outubro de 2007. Disponível em: http://portal.anvisa.gov.br/legislacao/?inheritR edirect=true\#/visualizar/26562. Acesso em: 5 jul. 2010. 
BRASIL. Lei n. 8.080, de 19 de setembro de 1990. Dispõe sobre as condições para a promoção, proteção e recuperação da saúde, a organização e o funcionamento dos serviços correspondentes e dá outras providências. Disponível em: http://www.planalto.gov.br/ccivil_03/leis/L8080.htm. Acesso em: 14 fev. 2018.

BRASIL. Ministério da Saúde. $8^{a}$ Conferência Nacional de Saúde. Relatório Final. 1986. Disponível em: http://conselho.saude.gov.br/biblioteca/Relatorios/relatorio_8.pdf. Acesso em: 20 jan. 2018.

CARDOSO, Michelle Rodrigues; FERRO, Luís Felipe. Saúde e população LGBT: demandas e especificidades em questão. Psicologia: Ciência e Profissão, Brasília, v. 32, n. 3, p. 552-63, 2012. Disponível em: http:// www.scielo.br/scielo.php?script=sci_arttext\&pid=S1414-98932012000300003\&lng=en\&nrm=iso. Acesso em: 20 mar. 2018. http://dx.doi.org/10.1590/S1414-98932012000300003.

FACCHINI, Regina. Histórico de luta LGBT no Brasil. In: CONSELHO Regional de Psicologia da 6 a Região (Org.). Psicologia e diversidade sexual. São Paulo: CRPSP, 2011.

FAGUNDES, Helenara Silveira; KREUTZ, Ineiva Terezinha; CASTAMAN, Daniela. Políticas Públicas, Sujeitos Profissionais e a Fronteira Arco Sul. Sociedade em Debate, Pelotas, RS, v. 24, n. 1, p. 93-110, jan./abr. 2018. Disponível em: http://revistas.ucpel.tche.br/index.php/rsd/article/view/1681. Acesso em: 10 jul. 2019.

FLEURY, Sonia; OUVERNEY, Assis Mafort. Política de saúde: uma política social. In: GIOVANELLA, Lígia (Org.). Políticas e Sistema de Saúde no Brasil. Rio de Janeiro: Editora Fiocruz, 2008. 1112 p.

GADELHA, Carlos Augusto Gorbois; COSTA, Laís. Integração de fronteiras: a saúde no contexto de uma política nacional de desenvolvimento. Cadernos de Saúde Pública, Rio de Janeiro, v. 23, sup. 2, 2007. Disponível em: http://www.scielo.br/pdf/csp/v23s2/10.pdf. Acesso em: 29 abr. 2010.

GIOVANELLA, Ligia et al. Saúde nas fronteiras: acesso e demandas de estrangeiros e brasileiros não residentes ao SUS nas cidades de fronteira com países do MERCOSUL na perspectiva dos secretários municipais de saúde. Cadernos de Saúde Pública, Rio de Janeiro, v. 23, sup. 2, p. S251-S266, 2007. Disponível em: http://www.scielo.br/pdf/\%0D/csp/v23s2/13.pdf. Acesso em: 11 jun. 2018.

GIOVANELLA, Ligia. Saúde nas fronteiras: estudo do acesso aos serviços de saúde nas cidades de fronteira com países do MERCOSUL. 2004. Projeto de Pesquisa. Disponível em: http://www.ensp.fiocruz.br/portalensp/saudefronteiras/pdf/projeto.pdf. Acesso em: 16 nov. 2009.

KLEBA, Maria Elisabeth. Descentralização do Sistema de Saúde no Brasil. Chapecó, SC: Argos, 2005. 476 p.

LOZA, Oralia; ALVAREZ, Carlos R.; PERALTA-TORRES, David. Healthcare and social services providers who serve sexual and gender minorities in a U.S.-Mexico Border City. J Immigrant Minority Health, v. 20, n. 6, p. 1537-40, 2018.

MARQUES, Maria Cristina da Costa. A história de uma epidemia moderna: a emergência política da Aids/ HIV no Brasil. São Carlos, SP: RiMa; Maringá: EDUEM, 2003.

MELLO, Luiz; BRITO, Walderes; MAROJA, Daniela. Políticas públicas para a população LGBT no Brasil: notas sobre alcances e possibilidades. Cadernos Pagu, Campinas, SP, n. 39, p. 403-29, jul./dez. 2012. Disponível em: http://www.scielo.br/scielo.php?script=sci_arttext\&pid=S0104-83332012000200014\&lng=en\&nrm =iso. Acesso em: 20 mar. 2018. DOI: http://dx.doi.org/10.1590/S0104-83332012000200014

MeRCOSUL. Comissão Permanente LGBT. [s.d.]. Disponível em: http://www.raadh.mercosur.int/pt-br/ comissoes/lgbt/. Acesso em: 3 mar. 2018. 
MERCOSUL. Objetivos do Mercosul. [s.d.]. Disponível em: https://www.mercosur.int/quienes-somos/ objetivos-del-mercosur/. Acesso em: 28 fev. 2018.

MERCOSUL. RAADH-Reunião de Altas Autoridades sobre Direitos Humanos e Chancelarias do Mercosul e Estados Associados. [s.d.]. Disponível em: http://www.raadh.mercosur.int/pt-br/. Acesso em: 3 mar. 2018

OLIVEIRA, Robson Bruniera de. Vigilância epidemiológica de fronteiras terrestres do Arco Sul do Brasil. 2015. 135 f. Tese (Doutorado em Epidemiologia em Saúde Pública) - Escola Nacional de Saúde Pública Sergio Arouca, Rio de Janeiro, 2015.

OPAS/OMS. Informe de la Trifrontera: Estúdio de Red Fronteriza Brasil, Argentina, Paraguai, 2001 e 2002. Disponível em <http://bvsms.saude.gov.br/bvs/publicacoes/Espanhol.pdf> Acesso em 12 Abr. 2019

ORGANIZAÇÃO DAS NAÇÕES UNIDAS NO BRASIL. Discriminação impede que pessoas LGBT tenham acesso à saúde, alerta OPAS. 2016. Disponível em: https://nacoesunidas.org/discriminacao-impede-que-pessoasIgbt-tenham-acesso-a-saude-alerta-opas/. Acesso em: 14 fev. 2018.

PAIM, Jairnilson Silva. O que é o SUS?. Rio de Janeiro: Editora Fiocruz, 2009. 148 p. (Coleção Temas em Saúde).

PAULA, Carlos Eduardo Artiaga; SILVA, Ana Paula da; BITTAR, Cléria Maria Lôbo. Vulnerabilidade legislativa de grupos minoritários. Ciência \& Saúde Coletiva, Rio de Janeiro, v. 22, n. 12, p. 3841-8, dez. 2017. Disponível em: http://www.scielo.br/scielo.php?script=sci_arttext\&pid=S1413-81232017021203841\&ln g=pt\&nrm=iso. Acesso em: 4 fev. 2018. DOI: http://dx.doi.org/10.1590/1413-812320172212.24842017.

PEITER, Paulo César. Geografia da saúde na faixa da fronteira continental do Brasil na passagem do milênio. 2005. Tese (Doutorado em Geografia)- Universidade Federal do Rio de Janeiro, Rio de Janeiro, 2005.

PREUSS, Lislei Teresinha. O Direito à saúde na fronteira: duas versões sobre o mesmo tema. 2007. $172 f$. Dissertação (Mestrado em Serviço Social), Programa de Pós-graduação em Serviço Social, Universidade Federal de Santa Catarina, 2007.

PREUSS, Lislei Teresinha. O pacto pela saúde nas cidades-gêmeas da fronteira do Rio Grande do Sul com a Argentina e o Uruguai. 2011. 178f. Orientadora: Idilia Fernandes. Tese (Doutorado em Serviço Social)Pontifícia Universidade Católica do Rio Grande do Sul, Porto Alegre, RS, 2011.

REIS, Toni. O movimento homossexual. In: FIGUEIREDO, Mary Neide Damico (Org.). Homossexualidade e educação sexual: construindo o respeito à diversidade. Londrina, PR: EdUEL, 2007.

SALLA, Fernando et al. Violência e gestão das fronteiras do Brasil. Revista Segurança, Justiça e Cidadania, Brasília, ano 4, n. 8, p. 9-28, 2014. Disponível em: http://www.justica.gov.br/sua-seguranca/segurancapublica/analise-e-pesquisa/download/revista_seguranca/revista-seguranca-justica-e-cidadania_numero-8. pdf. Acesso em: 17 fev. 2018.

SILVA, José Afonso da. Curso de Direito Constitucional Positivo. 25 Ed. São Paulo: Malheiros, 2005. 924 p.

SIMÕES, Julio Assis; FACCHINI, Regina. Do movimento homossexual ao LGBT. São Paulo: Editora Fundação Perseu Abramo, 2009. 196 p.

UNAIDS. AMAZONAIDS: na fronteira uma epidemia. 2016. Disponível em: https://unaids.org.br/wpcontent/uploads/2017/05/2017_AMAZONAIDS_Nafronteiradeumaepidemia_low.pdf. Acesso em: 1음 mar. 2018. 
WILDER-SMITH, A; HILL, D.R; FREEDMAN, D.O. The Revised International Health Regulations (2005): Impact on Yellow Fever Vaccination in Clinical Practice. American Journal of Tropical Medicine and Hygiene, $v$. 78, n. 3, p. 359-60, 2008.

\section{Sobre os autores:}

Lislei Teresinha Preuss - Doutora em Serviço Social pela Pontifícia Universidade Católica do Rio Grande do Sul (PUC-RS). Mestre em Serviço Social e graduada em Serviço Social pela Universidade Federal de Santa Catarina (UFSC). Graduada em Pedagogia com ênfase em Orientação Educacional pela Universidade do Estado de Santa Catarina (UDESC). Professora Adjunta do Departamento de Serviço Social e do Programa de Pós-Graduação em Ciências Sociais Aplicadas da Universidade Estadual de Ponta Grossa (UEPG/PR). E-mail: lisleipreuss@hotmail.com, Orcid: http://orcid.org/0000-0001-5786-7228

Dilermando Aparecido Borges Martins - Mestre em Ciências Sociais Aplicadas e bacharel em Direito pela Universidade Estadual de Ponta Grossa (UEPG). Professor da Universidade do Norte do Paraná (UNOPAR) e Faculdade de Jaguariaíva (FAJAR). E-mail: dilerborges@hotmail.com, Orcid: http://orcid.org/0000-0001-9638-9169 